\title{
New Level, New Beginning: the 2015 NSCGT-CCGC Tournament
}

\author{
Qiang Gao ${ }^{1}$ \\ Shenyang, China
}

The National Student Computer Games Tournament and the Chinese Computer Games Championship (NSCGT-CCGC), sponsored by the chess game management center, General Administration of Sport of China (GASC, a government department of China) and the Chinese Association for Artificial Intelligence (CAAI) and the College Steering Committee of Computer Science and Technology Education (CSC-CSTE), were held with ceremonies in Beijing, China, Sept. 18-20, 2015.

There were seventeen kinds of games in this NSCGT-CCGC which are listed as follows:

Chinese Chess, Go $19 \times 19$, Go $13 \times 13$, Go $9 \times 9$, Chinese Army Chess, Connect6, Dots \& Boxes, EinStein Würfelt Nicht!, Checkers $8 \times 8$, Checkers $10 \times 10$, Gomoku, Two-on-one poker, Bridge, Surakarta, Amazons, Phantom Go and NoGo.

More than 210 teams with a total of 300 students and teachers from 30 universities or as individuals participated in this tournament so this was an unprecedented tournament.

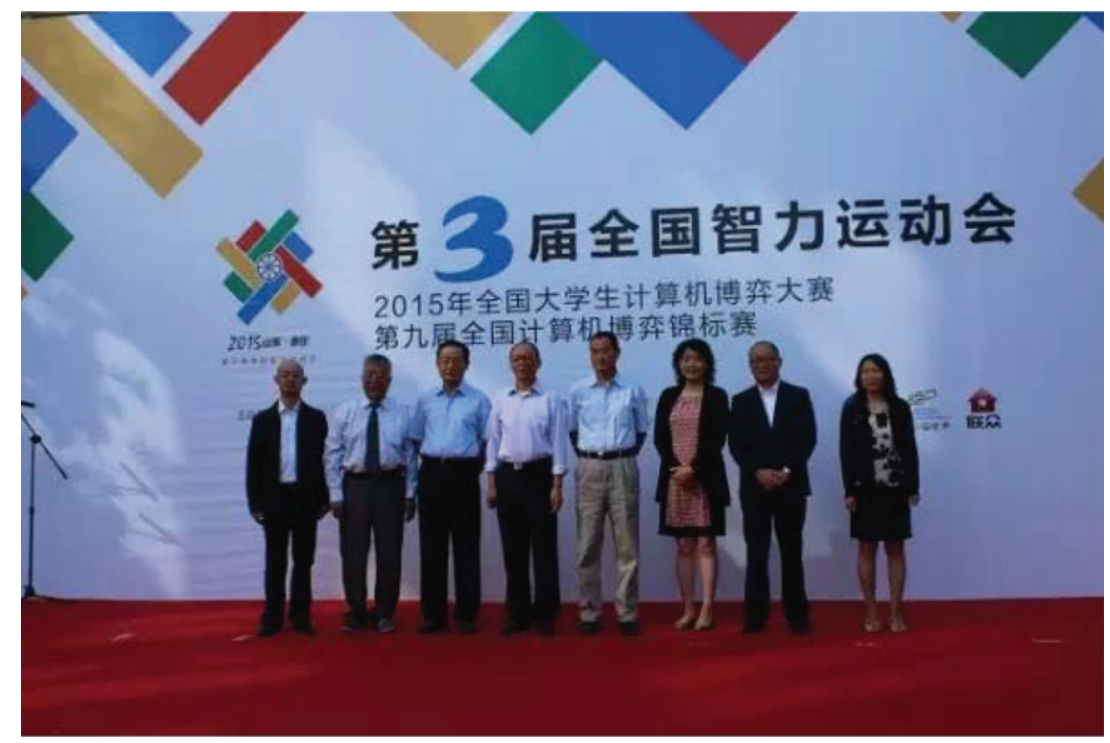

Fig. 1. The group photo of honored guests.

The following attended the opening ceremony of the tournament: Prof. Deyi Li who is the director of CAAI and academician of China Engineering Academy, Jun'an Yang who is the director of

\footnotetext{
${ }^{1}$ Computer Games Group, Northeastern University, Shenyang, 110004 P.R. China. E-mail: xuxinhe@ ise.neu.edu.cn
} 


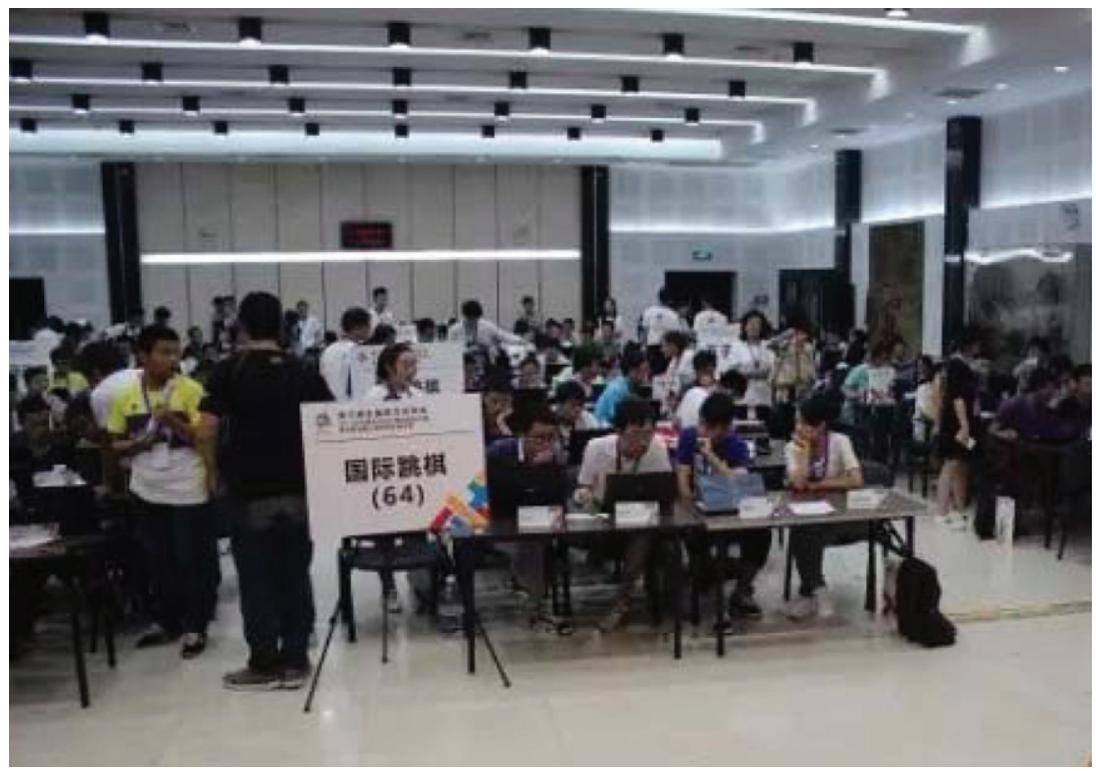

Fig. 2. The venue of the games tournament.

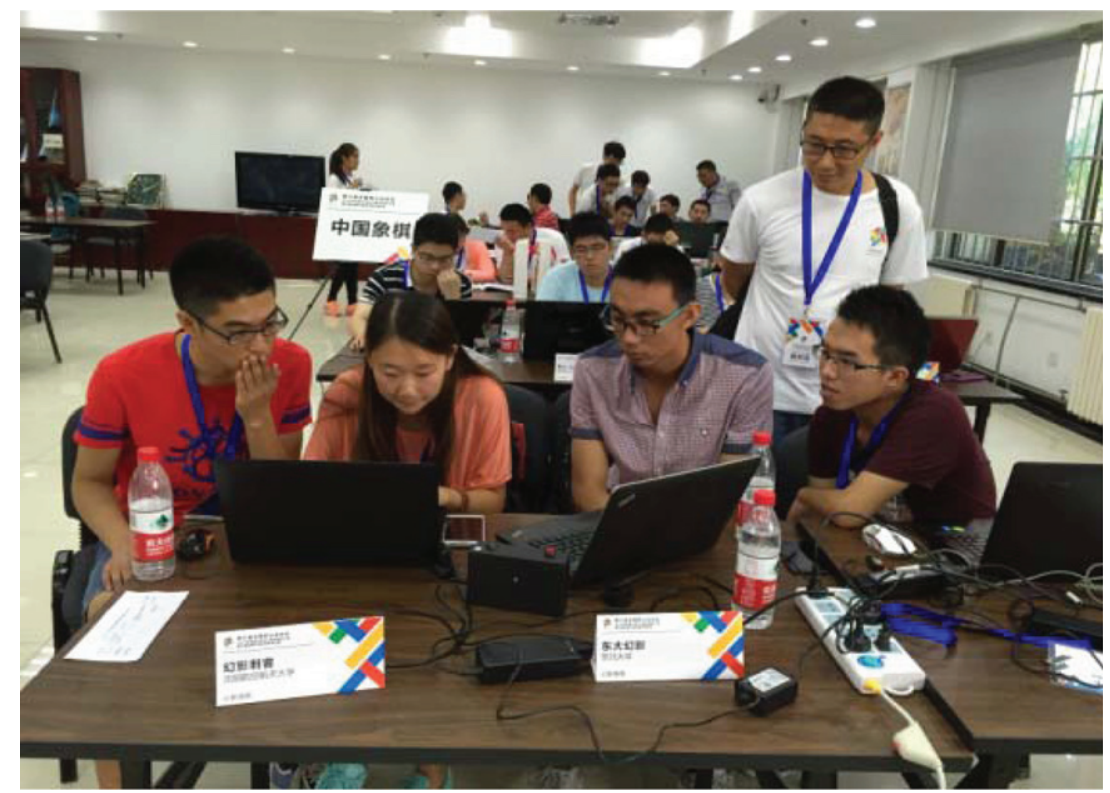

Fig. 3. The venue for Phantom Go.

chess game management center, GASC, Prof. Fangchun Yang who is the vice-director of CAAI and vice-president of Beijing University of Posts and Telecommunications, Prof. Xinhe Xu who is the chairman of the organizing committee and Prof. Yajie Wang, who is the director of Technical Committee of Computer Games (TCCG) which belongs to CAAI and vice-chairman of the organizing committee. 
Table 1

The number of teams participating in every game

\begin{tabular}{|c|c|c|c|c|c|c|c|}
\hline Game & Amazons & Connect6 & $\begin{array}{c}\text { Chinese } \\
\text { Chess }\end{array}$ & $\begin{array}{c}\text { Dots \& } \\
\text { Boxes }\end{array}$ & $\begin{array}{c}\text { Go } \\
19 \times 19\end{array}$ & $\begin{array}{c}\text { Go } \\
13 \times 13\end{array}$ & $\begin{array}{c}\text { Go } \\
9 \times 9\end{array}$ \\
\hline \# of Teams & 20 & 30 & 8 & 18 & 7 & 4 & 5 \\
\hline
\end{tabular}

\begin{tabular}{|c|c|c|c|c|c|c|c|}
\hline Game & NoGo & Surakarta & $\begin{array}{c}\text { Phantom } \\
\text { Go }\end{array}$ & $\begin{array}{c}\text { Checkers } \\
8 \times 8\end{array}$ & $\begin{array}{c}\text { Checkers } \\
10 \times 10\end{array}$ & $\begin{array}{c}\text { Ein Stein } \\
\text { Würfelt } \\
\text { Nicht }\end{array}$ & Bridge \\
\hline \# of Teams & 13 & 19 & 10 & 6 & 14 & 18 & 5 \\
\hline
\end{tabular}

\begin{tabular}{|c|c|c|c|}
\hline Game & Gomoku & $\begin{array}{c}\text { Chinese } \\
\text { Army Chess }\end{array}$ & $\begin{array}{c}\text { Two-on-one } \\
\text { poker }\end{array}$ \\
\hline \# of Teams & 11 & 12 & 12 \\
\hline
\end{tabular}

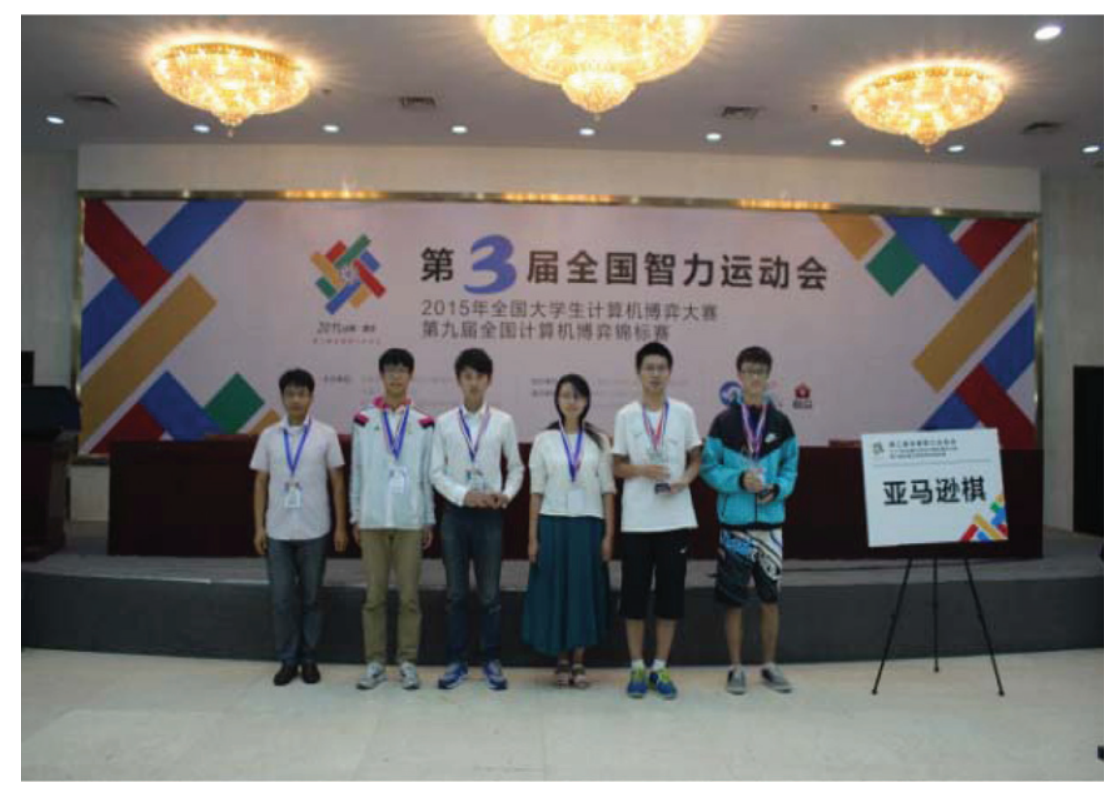

Fig. 4. The chief referee (first from the left) and the winners.

At the opening ceremony Prof. Xinhe Xu reviewed the development of Chinese computer games and thought that this tournament was different from any previous one. Firstly, it was included in the 3rd Session of The National Mind Sports Games (NMSG). Secondly, it was supported by the chess game management center, GASC. Thirdly, it was held in the China Chess institute, the highest chess academy in China. So this is a milestone for Chinese computer games. He proposed that the most important thing for students should be to participate in the games and learn to communicate with each other. Jun'an Yang expressed his support for computer games tournaments and said that it was a new project of NMSG and could interact with chess games. Computer games can bring out the potential for innovation in students and promote the development of chess games. Prof. Deyi Li said that human brain and computer could help each other and promote the development of intelligence. He hoped that human brain and computer could live in harmony while teachers and students could do cross-over studies between traditional science and artificial intelligence or study computer games. Let's welcome the arrival of a new species - robot. 
CCGC has been organized ten times since 2006. The number of games has increased to 17 from one, Chinese Chess, of the 2006 CCGC and there are more than 300 participants in this tournament compared to only dozens of participants in the past, so the level of Chinese computer games kept rising all the time. Table 1 listed the number of teams for each game.

According to the rules of the tournament, no more than two teams from each university can sign up for each game so many universities have held campus competitions before coming to the tournament. Otherwise the scale of the tournament would have been even bigger.

The tournament this year adds some new games, such as Bridge, Checkers $8 \times 8$ and Gomoku, which covers all the games of NMSG. Because the committee of the tournament strongly emphasizes that no copycat programs are permitted to participate in the games, we invited many professional teachers to judge each game which made our competition go on smoothly and successfully. After two days' fierce competition, the tournament ended successfully and all the participants benefitted greatly and were very happy to return to their studies.

As Prof. Xinhe Xu said at the opening ceremony, China is a big country of computer games but it is not powerful enough. If all the teams of each participating school were totalled up, there would be nearly 1000 teams with some 3000 staff who are doing research on computer games. However, there still exists a great gap compared with the international top level in some kinds of computer games, such as chess, Go, Checkers and so on. There is not enough innovative research on the relevant theories such as the algorithms for computer games in China. However, given the development of computer game activity in the past ten years, we believe that China can surely become a powerful country of computer gaming in the near future. 